\title{
Increased excitability in tat-transgenic mice: Role of tat in HIV-related neurological disorders
}

\author{
Silvia Zucchini a,b,*,1, Anna Pittaluga ${ }^{\mathrm{c}, \mathrm{d}, 1}$, Egidio Brocca-Cofano ${ }^{\mathrm{e}, 1}$, Maria Summa ${ }^{\mathrm{c}, \mathrm{d}}$, Marina Fabris ${ }^{\mathrm{e}}$, \\ Rita De Michele ${ }^{\mathrm{e}}$, Angela Bonaccorsi ${ }^{\mathrm{e}}$, Graziella Busatto ${ }^{\mathrm{f}}$, Giuseppe Barbanti-Brodano ${ }^{\mathrm{g}}$, Giuseppe Altavilla ${ }^{\mathrm{f}}$, \\ Gianluca Verlengia ${ }^{\mathrm{a}}$, Pierangelo Cifelli ${ }^{\mathrm{a}, \mathrm{h}}$, Alfredo Corallini ${ }^{\mathrm{g}}$, Antonella Caputo ${ }^{\mathrm{e}, 2}$, Michele Simonato ${ }^{\mathrm{a}, \mathrm{b}, 2}$ \\ a Department of Medical Sciences, Neuroscience Center, University of Ferrara, National Institute of Neuroscience, Italy \\ b Laboratory of Technologies for Advanced Therapy (LTTA), Technopole of Ferrara, Italy \\ c Department of Pharmacy, Section of Pharmacology and Toxicology, University of Genoa, Italy \\ d Center of Excellence for Biomedical Research, University of Genoa, Italy \\ e Department of Molecular Medicine, University of Padua, Italy \\ ${ }^{\mathrm{f}}$ Department of Medicine, University of Padua, Italy \\ ${ }^{g}$ Department of Experimental and Diagnostic Medicine, Section of Microbiology, University of Ferrara, Italy \\ ${ }^{\mathrm{h}}$ RiMED Foundation, Palermo, Italy
}

\section{A R T I C L E I N F O}

\section{Article history:}

Received 31 August 2012

Revised 3 February 2013

Accepted 19 February 2013

Available online 27 February 2013

\section{Keywords:}

HIV-1-tat-transgenic mice

HIV-1 associated neurocognitive disorders

Seizures

Kainate

Neurodegeneration

\begin{abstract}
A B S T R A C T
HIV-1 associated neurocognitive disorders (HAND) are a major complication of HIV-1 infection. The mechanism(s) underlying HAND are not completely understood but, based on in vitro studies, the HIV-1 Tat protein may play an important role. In this study, the effect of prolonged exposure to endogenously produced Tat in the brain was investigated using a tat-transgenic (TT) mouse model constitutively expressing the HIV-1 tat gene. We found that stimulus-evoked glutamate exocytosis in the hippocampus and cortex was significantly increased in TT as compared with wild-type control (CC) mice, while GABA exocytosis was unchanged in the hippocampus and decreased in the cortex. This suggests that Tat generates a latent hyper-excitability state, which favors the detrimental effects of neurotoxic and/or excitotoxic agents. To challenge this idea, TT mice were tested for susceptibility to kainate-induced seizures and neurodegeneration, and found to exhibit significantly greater responses to the convulsant agent than CC mice. These results support the concept that constitutive expression of tat in the brain generates a latent excitatory state, which may increase the negative effects of damaging insults. These events may play a key role in the development of HAND.
\end{abstract}

(c) 2013 Elsevier Inc. All rights reserved.

\section{Introduction}

HIV-1 associated neurocognitive disorders (HAND), a major complication of HIV-1 infection, comprise mild (minor neurocognitive disorders, MND) to severe (HIV-1 associated dementia, HAD) impairments (Lindl et al., 2010; Navia et al., 1986; Selnes, 2005; Singer et al., 2010; Tattevin et al., 2006). Seizures are often observed in HAND patients (Bartolomei et al., 1999; Modi et al., 2002).

The mechanism(s) underlying HAND are not completely understood. Histologically, brain biopsy material exhibits microglial activation, neuronal loss, astrocytosis, vasculitis and demyelination (Everall et al., 1999; Lindl et al., 2010; Masliah et al., 1992). However, only perivascular

\footnotetext{
* Corresponding author at: Department of Clinical and Experimental Medicine, Section of Pharmacology, University of Ferrara, Via Fossato di Mortara 17-19, 44121 Ferrara, Italy. Fax: + 390532455205

E-mail address: silvia.zucchini@unife.it (S. Zucchini).

Available online on ScienceDirect (www.sciencedirect.com).

1 S. Zucchini, A. Pittaluga and E. Brocca-Cofano equally contributed to the study.

${ }^{2}$ M. Simonato and A. Caputo share the position of senior author.
}

macrophages and microglial cells are productively infected by the virus, while HIV replication is limited in astrocytes, and neurons are resistant to infection (Lindl et al., 2010). Infected cells may release viral components and/or soluble neurotoxins (e.g. chemokines, cytokines, excitatory amino acids) that alter neuronal function (Giulian et al., 1990; Kaul et al., 2005; Nath and Geiger, 1998).

Among viral components, the Tat protein may be particularly important in HAND pathogenesis. First, it is highly expressed in the brain of HIV-1 infected patients (Wessenligh, 1993; Westendorp et al., 1995). Second, besides its essential role for HIV-1 gene expression, replication and cell-to-cell transmission (Ensoli et al., 1993), it is actively released by infected cells and internalized by a variety of cells (Ferrari et al., 2003; Frankel and Pabo, 1988) where it translocates to the nucleus modulating the expression of transcription factors and cytokines (Mengozzi et al., 1999; Minghetti et al., 2004). Third, extracellular Tat may interact with surface receptors, including chemokine (Albini et al., 1998; Brailoiu et al., 2008; Eugenin et al., 2003), NMDA (Behnisch et al., 2004; Eugenin et al., 2007; Longordo et al., 2006; Prendergast et al., 2002) and G protein coupled receptors (Feligioni et al., 2003; Haughey 
et al., 1999; Musante et al., 2010), leading to impaired transmission (Behnisch et al., 2004) and/or neurotoxic events (Kim et al., 2003; King et al., 2006; Nath and Geiger, 1998; Sabatier et al., 1991).

Most studies have thus far been conducted in vitro, making it difficult to extrapolate the findings to the disease settings. Other studies were conducted in a mouse model in which the expression of Tat in astrocytes was inducible and experimentally restricted to defined time periods (Bruce-Keller et al., 2008; Kim et al., 2003). Here, we have evaluated the effect of prolonged exposure to Tat in the intact brain, using a tat-transgenic (TT) mouse model in which the tat gene is constitutively expressed, in a fashion similar to HIV-1 infection (Altavilla et al., 1999; Corallini et al., 1993). Phenotypic features of TT mice reminiscent of HIV-1 infection include tumors and Kaposi's sarcoma-like skin lesions (Altavilla et al., 1999; Corallini et al., 1993). We found that stimulus-evoked glutamate exocytosis in the hippocampus and cortex was significantly increased in TT as compared with wild-type control (CC) mice, while GABA exocytosis was decreased in the cortex and unchanged in the hippocampus. This suggests that Tat generates a latent hyper-excitability state, which favors the detrimental effects of neurotoxic and/or excitotoxic agents. In keeping with this idea, TT mice were found to be more susceptible to kainate-induced seizures and neurodegeneration than CC mice.

\section{Materials and methods}

\section{Animals}

Adult (6 to 8-month-old) male TT and CC mice were used for all experiments [a total of 43 CC and 59 TT mice, 31 of the latter with low skin phenotype and 28 with high skin phenotype (see below)]. The experimental procedures were approved by the Ethical Committees of the Universities of Ferrara and Genova, in accordance with the European legislation (EU Directive 2010/63/EU) and were approved by the Italian Ministry of Health (protocol number 29823-10). Experiments were performed following the Guide for the Care and the Use of laboratory animals of the National Institutes of Health (NIH publication no. 86-23, revised 1987). Adequate measure was taken to minimize pain or discomfort.

TT mice of the BDF strain carrying the complete HIV-1 tat cDNA were described previously (Altavilla et al., 1999; Corallini et al., 1993). CC animals were normal BDF mice. Two-month-old TT mice were routinely screened by PCR for the presence of the transgene on DNA extracted from the tail (as described below). tat-Positive male and female mice were separated and observed regularly twice a week. Male mice were controlled for the development of Kaposi's sarcoma-like skin lesions in the back (Altavilla et al., 1999; Corallini et al., 1993). These lesions develop in about $30 \%$ of the mice, starting from the third to the fifth month of age. The intensity of the lesions was given a score ranging from 0 (no lesions) to 6 . Scores correspond to: 0.5 , thickening of the skin and mild alopecia; 1 , intense alopecia with skin redness; 2 , alopecia and crusts; 3, deep and large lesions with several crusts; 4, crusts and partial exposure of dermis; 5 , exposure of the muscle layer; and 6, detachment of the skin from the muscle (Altavilla et al., 1999; Corallini et al., 1993).

\section{Genotyping and Tat expression analysis: PCR, RT-PCR and Western blot}

The genotype of each animal was assessed by PCR on genomic DNA isolated from the tail of two-month old mice and from the brain at the end of the experiments. The tat transgene was amplified using the primers 5'GAAGCATCCAGGAAGTCAGCC3' (forward), and 5'ACCTTCTTC TTCTATTCCTTCGGG3' (reverse), as described (Altavilla et al., 1999; Corallini et al., 1993). The control of the PCR reaction was pCV-Tat DNA, a plasmid containing an insert of complete tat cDNA (Arya et al., 1985). PCR products were analyzed by electrophoresis on $1.5 \%$ agarose-gels.
Tat expression in the brain was evaluated by means of real-time RT-PCR and Western blot analysis. To this purpose, the brains of CC and TT mice were manually divided in two parts (hemibrains) by a sagittal cut. One hemibrain was used to assess tat transcript levels, and the contralateral one was used to evaluate Tat protein expression. Total RNA was extracted from $100 \mathrm{mg}$ forebrain tissue using the Qiagen RNeasy Plus mini kit (Qiagen, Hilden, Germany), following the supplier's instructions. The quantity and the quality of the RNA were first evaluated by spectroscopy and verified by agarose gel electrophoresis. One $\mu \mathrm{g}$ RNA was then transcribed into cDNA using the QuantiTect Reverse Transcription kit (Qiagen).

Before retrotranscription into cDNA, the absence of contaminating DNA was controlled: RNA samples have been incubated in gDNA Wipeout buffer for $10 \mathrm{~min}$ at $42{ }^{\circ} \mathrm{C}$, as indicated in the QuantiTect Reverse Transcription kit (Qiagen). These RNA samples, together with the RNAs retrotranscribed into cDNA using the same QuantiTect Reverse Transcription kit (Qiagen) have been tested in PCR quantitative analysis. For the analysis of tat gene expression, the SYBR Green real-time PCR detection method was employed, using the QuantiTect SYBR green PCR kit (Qiagen). Primers for HIV-tat were 5'ATGGAGCCAGTAGATCCTA3' (forward) and 5'TGCTTTGATAGAGAAACTTGATG3' (reverse) (Peng et al., 2010). The primers for the housekeeping gene Rpl13 5'GTGAGGTGCCC TACAGTGAGATAC3' (forward) and 5'GATGGTGCGAGCCACTTTCTTG3' (reverse) were used in the same run as control for reverse transcription and for the normalization of tat gene expression values. After an initial step of denaturation at $95{ }^{\circ} \mathrm{C}$ for $5 \mathrm{~min}$, the qPCR run consisted of 35 cycles at $95{ }^{\circ} \mathrm{C}$ for $10 \mathrm{~s}$ and $54{ }^{\circ} \mathrm{C}$ for $30 \mathrm{~s}$. All samples were run in triplicate with the Real Time thermal analyzer Rotor-GeneTM 6000 (Corbett, Cambridge, UK). Data were normalized to the housekeeping gene Rpl13 and expressed as relative RNA levels: a TT(L) sample was used as reference and all data were divided by that reference value.

For Western blot analysis, the brain tissue from CC and TT mice (one animal per experiment) was homogenized in ice-cold lysis buffer ( 0.05 M Tris, pH 7.4, containing a protease inhibitor cocktail). Samples were incubated for $5 \mathrm{~min}$ on ice, before centrifuging at $14,000 \mathrm{rpm}$ for $45 \mathrm{~min}$ at $4{ }^{\circ} \mathrm{C}$. Collected supernatants $(20 \mu \mathrm{l} /$ lane $)$ and recombinant Tat solution (10-100 ng/20 $\mu \mathrm{l} / \mathrm{lane})$ were separated onto sodium dodecyl sulfate-polyacrylamide gel electrophoresis ( $10 \%$ polyacrylamide) and then transferred onto polyvinylidene fluoride membranes. Non-specific binding sites were blocked by incubating membranes for $1 \mathrm{~h}$ at room temperature with Tris-buffered saline (TBS buffer: $0.02 \mathrm{M}$ Tris, $0.150 \mathrm{M} \mathrm{NaCl}$, protease inhibitor cocktail, $\mathrm{pH}$ 7.4) containing $5 \%$ $(\mathrm{w} / \mathrm{v})$ non-fat dried milk. Membranes were then incubated overnight at $4{ }^{\circ} \mathrm{C}$ with mouse anti-Tat (mouse monoclonal, ID9D5 now EVA 3021; 1:500, NIBSC, Centre for AIDS Reagents) and anti- $\beta$-actin (mouse monoclonal; 1:2000, Sigma Aldrich Inc., St. Louis, MO) primary antibodies, the latter was used as an internal control. After extensive washings, membranes were incubated for $1 \mathrm{~h}$ at room temperature with an anti-mouse horseradish peroxidase-linked secondary antibody (1:2000, Sigma Aldrich Inc., St. Louis, MO) and immunoreactivity detected using an enhanced chemiluminescence Western blotting detection system (EuroClone, Milano, Italy).

\section{Neurotransmitter release}

CC and TT mice were killed by decapitation, brain cortices and hippocampi were rapidly removed, and purified synaptosomes were prepared within minutes, according to Dunkley et al. (1986), with minor modifications. In order to evaluate tat expression, the remaining brain tissue was used for RNA and protein extractions, as described above. Cortical and hippocampal tissues were homogenized in 10 volumes of $0.32 \mathrm{M}$ sucrose, and buffered to $\mathrm{pH} 7.4$ with Tris (final concentration $0.01 \mathrm{M}$ ) using a glass Teflon tissue grinder (clearance $0.25 \mathrm{~mm}$ ). The homogenate was centrifuged at $1000 \times g$ for 5 min to remove nuclei and debris, and the supernatant was gently stratified on a discontinuous Percoll gradient $(6 \%, 10 \%$, and $20 \% \mathrm{v} / \mathrm{v}$ in Tris-buffered sucrose) and 
centrifuged at $33,500 \times g$ for $5 \mathrm{~min}$. The layer between $10 \%$ and $20 \%$ Percoll (synaptosomal fraction) was collected and washed by centrifugation. The synaptosomal pellets were always resuspended in a physiological medium (superfusion medium) having the following composition (mM): $\mathrm{NaCl}, 125 ; \mathrm{KCl}, 3 ; \mathrm{MgSO}_{4}, 1.2 ; \mathrm{CaCl}_{2}, 1.2 ; \mathrm{NaH}_{2} \mathrm{PO}_{4}, 1 ; \mathrm{NaHCO}_{3}$, 22; glucose, 10 ; $\mathrm{pH} 7.2-7.4$, and aeration with $95 \% \mathrm{O}_{2}$ and $5 \% \mathrm{CO}_{2}$. The medium contained aminooxyacetic acid $(50 \mu \mathrm{M})$ to avoid GABA metabolism. Synaptosomal protein contents were determined according to Bradford (1976).

Identical portions of the synaptosomal suspensions were layered on microporous filters at the bottom of parallel superfusion chambers (Ugo Basile, Comerio, Varese, Italy) thermostated at $37{ }^{\circ} \mathrm{C}$ and superfused at $0.5 \mathrm{ml} / \mathrm{min}$ with a standard physiological solution aerated with $95 \%$ $\mathrm{O}_{2}$ and $5 \% \mathrm{CO}_{2}$. The synaptosomal protein content amounted to $0.23 \pm 0.074 \mathrm{mg}$ protein/chamber. It should be stressed that this technique is particularly appropriate to investigate presynaptic receptors. In fact, the continuous up-down superfusion of the synaptosome monolayers prevents indirect effects due to any released compound, i.e. endogenous compounds are immediately removed and cannot activate targets located on the neighboring nerve terminals (Musante et al., 2011). Thus, if any endogenous Tat was produced and released by synaptosomes, it would have been immediately removed and could not have affected neurotransmitter release.

In experiments aimed at investigating the impact of exogenous Tat on the spontaneous release of endogenous glutamate and GABA from CC synaptosomes, synaptosomes were equilibrated during 36 min of superfusion and then 4 consecutive 3-min fractions (termed b1-b4) were collected. The Tat protein (HIV-1 Clade B HAN2, Centre for AIDS Reagents, UK) was introduced at the end of the first fraction (b1; $\mathrm{t}=39 \mathrm{~min}$ ) and maintained until the end of the superfusion. When studying the impact of Tat on endogenous glutamate and GABA exocytosis evoked by a mild depolarizing stimulus, CC cortical and hippocampal synaptosomes were transiently (90 s at $\mathrm{t}=39 \mathrm{~min}$ ) exposed to a solution containing $12 \mathrm{mM} \mathrm{KCl}(\mathrm{NaCl}$ substituting for an equimolar concentration of $\mathrm{KCl}$ ). Tat was added concomitantly to the depolarizing stimulus. In these experiments, fractions were collected according to the following scheme: two 3-min fractions (basal release), one before $(t=36-39 \mathrm{~min}, \mathrm{~b} 1)$ and one after $(t=45-48 \mathrm{~min}, \mathrm{~b} 3)$ a 6-min sample $(t=39-45$ min; evoked release, b2) containing the transmitter released by the depolarizing stimulus. When indicated, Tat was denatured by heating it at $90{ }^{\circ} \mathrm{C}$ for 30 min and then added to the superfusion medium. Superfusion was always performed with a medium containing dialyzed $0.1 \%$ Polypep to avoid Tat sticking to glass walls and tubings.

Collected fractions and superfused synaptosomes were analyzed for the endogenous neurotransmitter content. Endogenous glutamate and GABA were measured by HPLC analysis after precolumn derivatization with o-phthalaldehyde and separation on a C18 reverse-phase chromatographic column $\left(10 \times 4.6 \mathrm{~mm}, 3 \mu \mathrm{m}\right.$; at $30{ }^{\circ} \mathrm{C}$; Chrompack, Middleburg, The Netherlands) coupled with fluorimetric detection (excitation wavelength, $350 \mathrm{~nm}$; emission wavelength, $450 \mathrm{~nm}$ ). Buffers and gradient program are described elsewhere (Luccini et al., 2007). Homoserine was used as an internal standard.

The amount of endogenous amino acid from synaptosomes in each superfusate fraction was expressed as picomoles per milligram of protein ( $\mathrm{pmol} / \mathrm{mg}$ protein). The effects of Tat on the basal release of endogenous transmitters were evaluated by calculating the ratio between the amino acid content in the fraction where the maximal effect was reached (the third fraction collected) and the amount in the first fraction and comparing this ratio with the corresponding ratio obtained under control conditions (no drug added). The high $\mathrm{K}^{+}$-induced overflow was estimated by subtracting the neurotransmitter content into the first and the third fractions collected (basal release, b1 and b3) from that in the 6-min fraction collected during and after the depolarization pulse (evoked release, b2).

\section{VGLUT immunohistochemistry}

CC and TT mice were killed and their brains were rapidly removed. One hemibrain was cut and used for RNA and protein extractions, as described above. The other hemibrain was immersed in $10 \%$ formaline and then paraffine-embedded. Coronal sections ( $6 \mu \mathrm{m}$ thick) were cut at the level of the dorsal hippocampus, mounted onto poly-lysine-coated slides and analyzed by immunohistochemistry as previously described (Paradiso et al., 2009; Zucchini et al., 2008). Briefly, sections were deparaffinized (2 washes in xylol $10 \mathrm{~min}, 5 \mathrm{~min}$ in ethanol 100\%, $5 \mathrm{~min}$ in ethanol 95\%) and then rehydrated in distilled water for $5 \mathrm{~min}$ and in PBS $1 \times$ for $10 \mathrm{~min}$. After incubation in $\mathrm{H}_{2} \mathrm{O}_{2} 3 \mathrm{~V}$ for $15 \mathrm{~min}$ at room temperature, they were rapidly rinsed in distilled water and washed again in PBS, then incubated with Ultra V Block (Ultra Vision Detection System; Lab Vision Corporation) for $5 \mathrm{~min}$ at room temperature, to block nonspecific background staining. After washing in PBS $1 \times$ for $5 \mathrm{~min}$, sections were incubated overnight at $4{ }^{\circ} \mathrm{C}$ in a humid atmosphere with the primary antibody against VGLUT (rabbit polyclonal; 1:500 dilution; Synaptic Systems). After rinsing in PBS $1 \times$, they were incubated with biotinylated goat anti-polyvalent serum (Ultra Vision Detection System) at room temperature for $10 \mathrm{~min}$, washed in PBS $1 \times$ for $5 \mathrm{~min}$ and then incubated in Streptavidin Peroxidase (Ultra Vision Detection System) at room temperature for $10 \mathrm{~min}$. The reaction product was detected as a brown substrate using a 3,3diaminobenzidinetetrahydrochloride (DAB) substrate kit for peroxidase (Vector Laboratories). Finally, sections were washed three times in PBS $1 \times(5$ min each $)$, counterstained with hematoxylin for $2 \mathrm{~min}$ and washed again in PBS $1 \times(5 \mathrm{~min})$. Coverslips were mounted using Gel/mount (Biomeda). The specificity of immunolabeling was verified in all experiments by controls in which the primary antibody was omitted (Supplementary Fig. S1). All tissues were processed identically and side-by-side, using the same solutions and reagents.

\section{Kainate treatment and seizure classification}

Kainate (Sigma-Aldrich) was administered i.p. (15 mg/kg), and the behavior of animals was observed for $2 \mathrm{~h}$ thereafter. This dose was chosen because it produces approximately half-maximal seizure responses in CC animals. Seizures were classified as follows (Bregola et al., 2002; Janumpalli et al., 1998): 1, chewing and drooling; 2, head nodding; 3, unilateral forelimb clonus; 4 , bilateral forelimb clonus; 5 , bilateral forelimb and hindlimb clonuses with falling; 6 , running or jumping seizure; 7 , tonic hindlimb extension; 8 , death. A previously described scoring system, the cumulative seizure score, was employed to estimate seizure susceptibility (Bregola et al., 2002). Seizure severity was rated as the sum of the scores recorded in each 5-min interval during the $2 \mathrm{~h}$ following kainate injection. The latency to the first severe (class 4 or higher) seizure was also recorded. The cumulative seizure score was statistically evaluated by using the Mann-Whitney $U$ test and the latency to the first severe seizure was evaluated by ANOVA and post-hoc Newman-Keuls tests.

\section{Analysis of neurodegeneration}

For the analysis of seizure-induced neurodegeneration, mice were killed $24 \mathrm{~h}$ after kainate administration, and their brains were fixed in $10 \%$ formaldehyde. First, the fixed brains were subjected to standard histological procedures and stained with hematoxilin and eosin to accurately identify the regions of interest. Damaged neurons were then detected using the Fluoro-Jade B (FJ) (Schmued and Hopkins, 2000), on coronal sections cut at the level of the dorsal hippocampus (Paxinos and Franklin, 2001). FJ analysis was conducted using a Leica microscope (DMRA2, Leica). The degree of cell damage was quantified blinded by two investigators, based on two distinct approaches. The first was a previously described scoring system named "neurodegeneration score" 
(Zucchini et al., 2002). The score range spanned from 0 (absence of FJ-positive neurons) to 7 (maximal neurodegeneration pattern). A score of 1 was given for the observation of fluorescent neurons either in the hilus, in the CA3 pyramidal layer, or in the CA1 pyramidal layer. Whenever a very intense neurodegeneration was observed in the CA3 or CA1 pyramidal layer (many positive cells with confluent fluorescence), the score related to that subarea was increased by 0.5 . Another 0.5 score was added when interneuronal fluorescence was detectable in the stratum oriens and/or radiatum. Therefore, the score related to CA3 and to CA1 could reach a maximal value of 2. Finally, when damage was observed in extra hippocampal regions (thalamus and cortex), the neurodegeneration score was further increased by 2 points. Thus, the maximal neurodegeneration score was 7: CA1 score 2 plus CA3 2 plus dentate gyrus 1 plus extra-hippocampal regions 2 . The second quantification method was based on the thresholding of FJ digital images (Paradiso et al., 2009; Zucchini et al., 2008). Images of the hippocampus were captured using a Leica DFC300FX camera and transformed into gray levels. Using Photoshop CS5, the hippocampus was cut out and the mean \pm standard deviation gray level was calculated. FJ-positive pixels were identified by thresholding at the gray level corresponding to the mean plus three standard deviations. Using this approach, only those pixels that were significantly above background (that is, positive to FJ) were selected. Data were then expressed as percent of FJ-positive pixels over total hippocampal pixels. Four regularly spaced sections (100 $\mu \mathrm{m}$ interval) were examined for each animal, and the score used for statistical analysis was the average of these multiple estimates. Alternatively, the mean percent of FJ-positive pixels in the 4 sections examined was calculated for each animal and used for statistical analysis.

NeuroTrace 594 red fluorescent (NT; Molecular Probes, Inc., Eugene, OR, USA) staining has been performed in a subset of brain sections after FJ staining, to identify degenerating neurons. After rehydration in 0.1 M PBS, ( $\mathrm{pH} 7.4$ ), sections were treated with PBS plus $0.1 \%$ Triton $\mathrm{X}-10010 \mathrm{~min}$, washed twice for $5 \mathrm{~min}$ in PBS then stained by NT (1:100), for $20 \mathrm{~min}$ at room temperature. Sections were washed in PBS plus $0.1 \%$ Triton $\mathrm{X}-100$, twice with PBS, then let stand for $2 \mathrm{~h}$ at room temperature in PBS.

\section{Statistical analysis}

For neurotransmitter release data, comparisons between experimental groups were performed by using ANOVA and post hoc the Dunnett's test. For in vivo data, ANOVA and post-hoc Newman-Keuls test were used for the analysis of latency and the Mann-Whitney $U$ test for the analysis of the cumulative seizure score. Differences between groups were considered significant when $\mathrm{P}<0.05$.

\section{Results}

\section{Expression of Tat in TT mice brain}

Male TT mice were monitored for the development of Kaposi's sarcoma-like skin lesions in the back. Based on the severity of the lesions, mice were divided in two groups, characterized, respectively, by low grade skin phenotype, TT(L), with lesion scores between 0 and 2, and high grade skin phenotype, TT(H), with lesion scores between 3 and 6 .

Expression of the tat gene in the brain of TT mice was then analyzed by real time RT-PCR analysis. No PCR amplification has been observed with RNA samples not transcribed into DNA (data not shown). The results reported in Fig. 1A show that tat mRNA is expressed in the brain of all TT mice. However, tat gene expression was higher in the brain of TT(H) mice as compared to TT(L) mice. Accordingly, expression of the Tat protein was detected in the brains of TT mice by Western blot analysis (Fig. 1B). In agreement with the results of real time RT-PCR, Tat protein expression differed between $\mathrm{TT}(\mathrm{H})$ and $\mathrm{TT}(\mathrm{L})$ mice, because it was clearly detectable only in mice displaying the high skin phenotype. These results confirm our previous data on tat gene expression in the tissues of TT mice (Altavilla et al., 1999; Corallini et al., 1993) and suggest that the skin phenotype can be used as a surrogate marker of tat gene expression in the brain, allowing to stratify the animals in the two subgroups for the subsequent experiments. Confirmation of the correct subgroup allocation of each mouse was obtained by RT-PCR at the end of the experiments.

\section{Effects of exogenous Tat administration on glutamate and GABA release}

It has been previously shown that exogenous Tat, while not affecting basal release, exerts opposite effects on glutamate and GABA overflow evoked by mild depolarization from nerve terminals isolated from the cortex of adult mice (Musante et al., 2010). These findings were confirmed in the present study. Acute Tat failed to affect the spontaneous release of both glutamate ( $1 \mathrm{nM}$ Tat: $92.7 \pm 6.8 \%$ of control, data from 3 experiments run in triplicate) and GABA ( $1 \mathrm{nM}$ Tat: $94.8 \pm 6.6 \%$, data from 3 experiments run in triplicate) in CC mice. Again consistent with the previous findings (Musante et al., 2010), Tat (0.03-3 nM) facilitated $12 \mathrm{mM} \mathrm{KCl}$-induced glutamate overflow in a concentration-dependent manner but inhibited GABA overflow from CC cortical nerve endings (Figs. 2A and B). Facilitation of glutamate as well as inhibition of GABA overflow could not be observed when exposing synaptosomes to a heat shock denatured protein (for glutamate: control: $294 \pm 22 \mathrm{pmol} / \mathrm{mg}$ prot; $1 \mathrm{nM}$ denatured Tat: $344 \pm 52 \mathrm{pmol} / \mathrm{mg}$ prot, n.s.; for GABA: control: $294 \pm 22 \mathrm{pmol} / \mathrm{mg}$ prot; $1 \mathrm{nM}$ denatured Tat: $314 \pm 37 \mathrm{pmol} / \mathrm{mg}$ prot, n.s; data from 3 experiments run in triplicate).

We then extended these data to hippocampal synaptosomes. In CC hippocampal synaptosomes, Tat had no effect on the spontaneous release of endogenous glutamate ( $1 \mathrm{nM}$ Tat: $95.8 \pm 4.3 \%$ of control, data from 3 experiments run in triplicate) and GABA ( $1 \mathrm{nM}$ Tat: $111.3 \pm 6.7 \%$ of control, data from 3 experiments run in triplicate). However, Tat (0.03-3 nM) concentration dependently facilitated the $12 \mathrm{mM} \mathrm{K}^{+}$-evoked glutamate overflow (Fig. 2C), while failing to modify that of GABA (Fig. 2D), at variance with the inhibition observed in the cortex. Again, Tat-induced changes in high $\mathrm{K}^{+}$-evoked glutamate overflow were prevented by protein heat shock denaturation (control: $189 \pm 18 \mathrm{pmol} / \mathrm{mg}$ prot; $1 \mathrm{nM}$ denatured Tat: $225 \pm 31 \mathrm{pmol} / \mathrm{mg}$ prot; n.s., data from three experiments run in triplicate).

\section{Glutamate and GABA release from nerve terminals isolated from TT mice}

The spontaneous and the depolarization-evoked release of endogenous glutamate and GABA was then investigated in cortical and hippocampal glutamatergic and GABAerigic nerve terminals isolated from CC, $\mathrm{TT}(\mathrm{L})$ and $\mathrm{TT}(\mathrm{H})$ mice. In both brain areas, the basal, spontaneous release of glutamate and GABA from TT mice did not significantly differ from that from CC mice (Fig. 3). However, the $12 \mathrm{mM} \mathrm{K}^{+}$-evoked glutamate overflow from cortical synaptosomes isolated from TT(L) was significantly increased compared with that from CC mice, and that from $\mathrm{TT}(\mathrm{H})$ was further and significantly increased compared with $\mathrm{TT}(\mathrm{L})$ mice (Fig. 3A), indicating that this effect correlates with the level of Tat expression in the brain. Similarly, the endogenous glutamate release induced by high $\mathrm{K}^{+}$from hippocampal terminals was increased in TT mice, and in TT(H) significantly more than in TT(L) (Fig. 3C). In contrast, the high $\mathrm{K}^{+}$-evoked release of GABA from TT cortical synaptosomes was significantly reduced when compared with CC mice, the maximum inhibition being observed in $\mathrm{TT}(\mathrm{H})$ mice (Fig. $3 \mathrm{~B}$ ), and that from hippocampal synaptosomes was not modified (Fig. 3D). Because of the features of the experimental approach we employed (the updown superfusion of synaptosomal monolayers) indirect effects due to residual endogenous Tat released by the nerve terminals could not account for changes in neurotransmitter release. In fact, the technique of superfusion ensures the immediate removal of released endogenous 
A

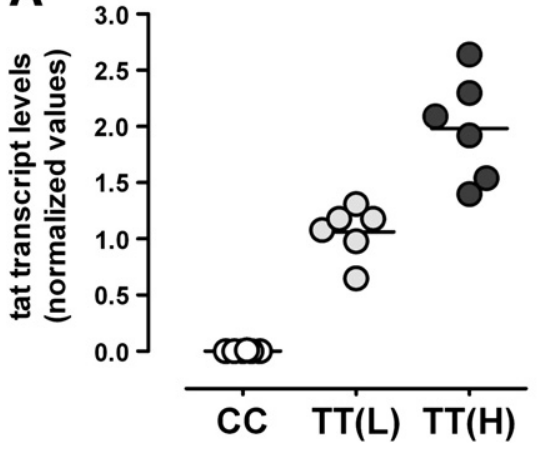

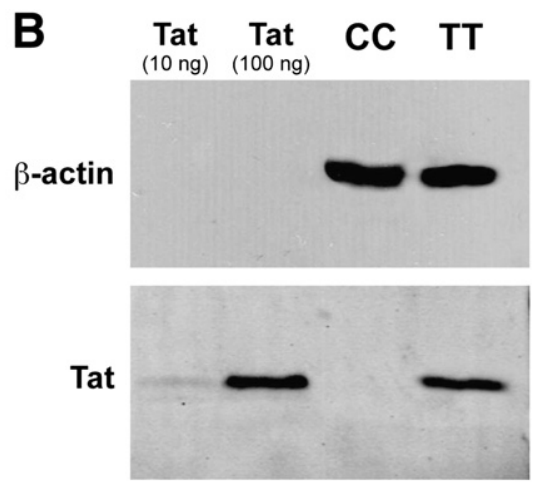

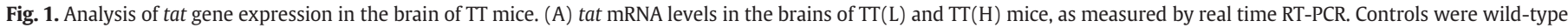

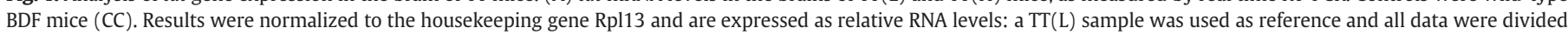

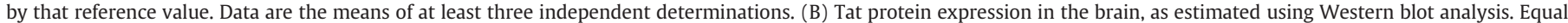

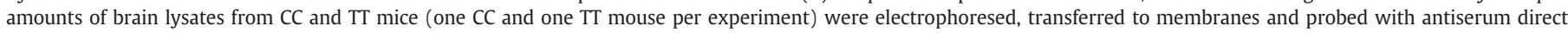

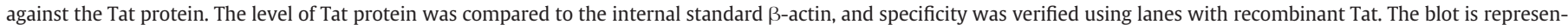
tative of the five blots of homogenates separately obtained from 5 CC and 5 TT mice, run in different days.

compounds, preventing indirect effects on the neighboring synaptosomes (Musante et al., 2011; Raiteri and Raiteri, 2000).

\section{VGLUT expression}

The observation that endogenous expression of Tat leads to the potentiation of glutamate release in a preparation in which nerve terminals are isolated (thus, not directly exposed to Tat at the time of the experiment) is puzzling. Possible interpretations of this finding may be that Tat can induce long-term increases in the amount of releasable glutamate, either by increasing the number of glutamatergic terminals or the density of glutamatergic vesicles within each terminal. The former hypothesis seems less likely because the basal $\left(\mathrm{Ca}^{2+}\right.$-independent, non-vesicular) release of glutamate should increase if the number of glutamatergic terminals increases (Muzzolini et al., 1997), and this was not the case in TT synaptosomes. To further investigate this idea, immunohistochemistry was used to assay expression of the glutamatergic vesicular transporter VGLUT1, a marker of glutamate release vesicles (Fadda et al., 2007). VGLUT1 immunoreactivity is normally abundant in many cortical and hippocampal areas, most prominently in the deeper
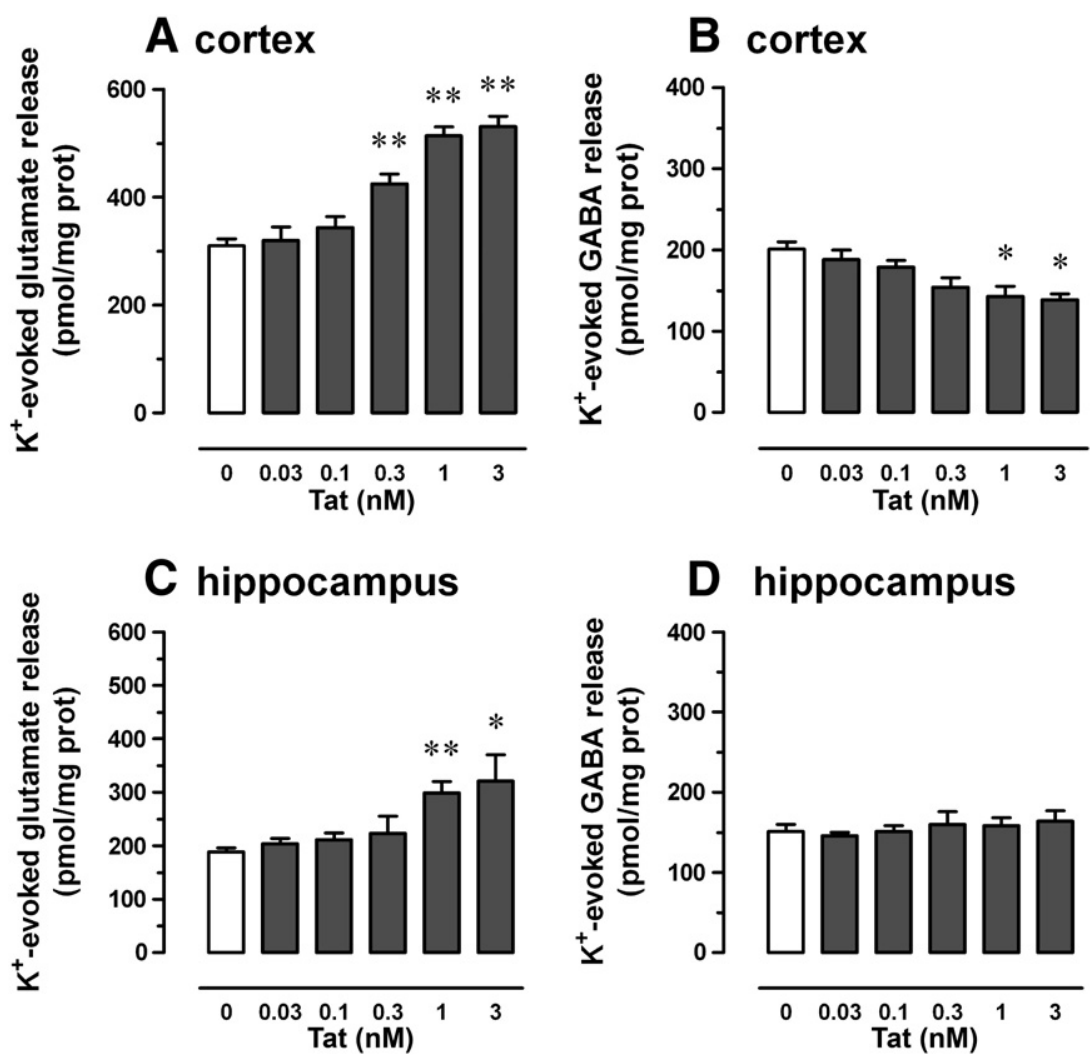

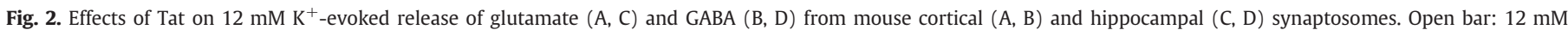

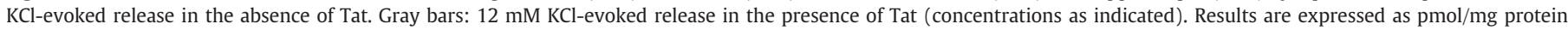

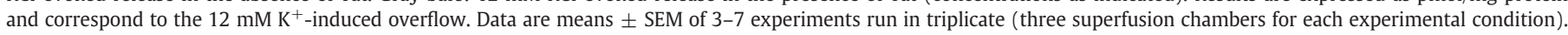
${ }^{*} \mathrm{P}<0.05$ vs. control; ${ }^{* *} \mathrm{P}<0.01$ vs. control; ANOVA and post hoc Dunnett's test. 

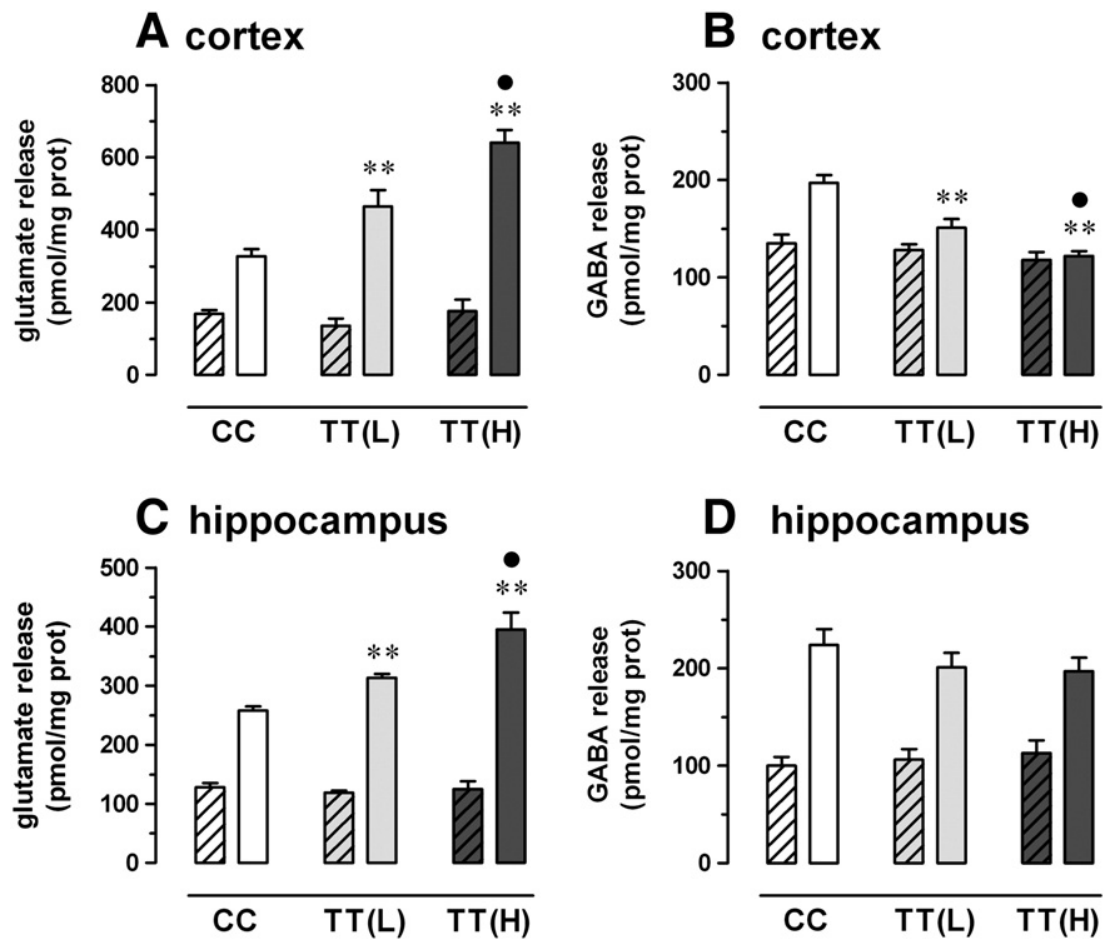

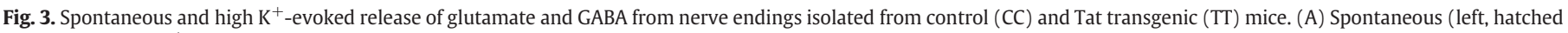

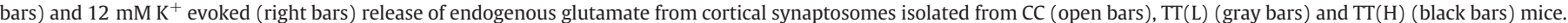

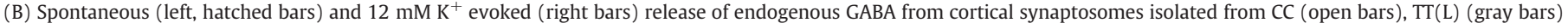

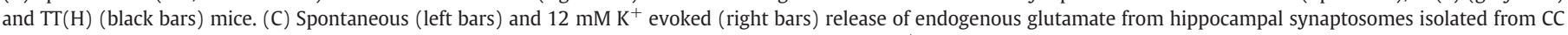

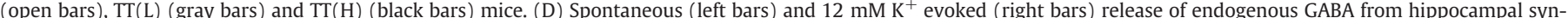

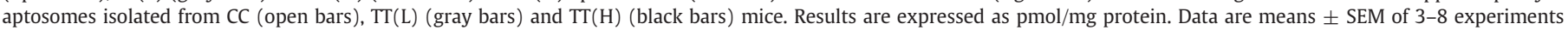
run in triplicate (three superfusion chambers for each experimental condition). ${ }^{* *} \mathrm{P}<0.01 \mathrm{vs}$. CC; $\bullet P<0.05$ vs. TT(L); ANOVA and post hoc Newman-Keuls test.

layers of the cortex and in the stratum oriens and radiatum of CA1, in the stratum oriens, lucidum and radiatum of CA3, and in the molecular layer and hilus of the dentate gyrus in the hippocampus. A clear enhancement of VGLUT1 immunoreactivity was observed both in the fronto-temporal cortex and in the hippocampus of TT, compared with CC mice (Fig. 4). Moreover, in keeping with the above findings on glutamate release, TT(H) mice displayed a stronger VGLUT-1 signal than TT(L) mice (Fig. 4).

Susceptibility of TT mice to kainate-induced seizures and to seizure-induced damage

The increased ratio between excitatory and inhibitory neurotransmissions in TT mice may implicate a greater susceptibility to seizures and to seizure-induced damage. To examine this possibility, animals in the three experimental groups were treated with the convulsant agent kainate. $\mathrm{TT}(\mathrm{H})$ mice displayed increased susceptibility to kainateinduced seizures, compared with CC mice and with $\mathrm{TT}(\mathrm{L})$ mice, because 1) latency to generalized seizure onset was significantly reduced (Fig. 5A), 2) seizure severity (cumulative seizure score) was significantly increased (Fig. 5B), and 3) mortality rate was dramatically increased (Fig. 5C). TT(L) mice were susceptible to kainate seizures like CC mice, but their mortality rate was higher (Fig. 5C).

Seizure-induced neurodegeneration was then analyzed in a subset of mice using Fluoro-Jade B (FJ), an anionic fluorescein derivative staining neurons undergoing degeneration (Schmued and Hopkins, 2000) and NeuroTrace (NT) to identify neurons. Numerous FJ-positive cells were observed in the brain of kainate-treated mice with high score seizures, while they were virtually absent in the brain of saline-treated mice or of mice showing low score seizures after kainate administration (Fig. 6). These degenerating cells were neurons, because they all double-labeled with NT (Supplementary Fig. S2). The degree of degeneration was related to the severity of seizures, i.e. with the cumulative seizure score, in all experimental groups. Thus, although $\mathrm{TT}(\mathrm{H})$ mice displayed higher scores both in terms of seizure severity and neurodegeneration, no significant difference in the degree of neurodegeneration was observed following similar grade seizures in $\mathrm{TT}(\mathrm{H})$ compared with CC mice (Fig. 7).

\section{Discussion}

The pathological mechanism(s) of HAND-associated brain lesions are still uncertain, but several lines of evidence suggest that Tat may play a key role. Tat is released by HIV-1 infected cells of many organs (Chang et al., 1997), is present at detectable levels in serum (Westendorp et al., 1995) and is capable of crossing the blood-brain barrier (Schwarze et al., 1999). Thus, peripherally-generated Tat may enter the CNS. Moreover, the Tat protein is produced directly in the brain of HIV-1-infected patients by cells of the glial and macrophage systems (Hudson et al., 2000).

The effects of Tat in the brain have been studied using several approaches. First, intraventricular injection in the rat brain has been reported to cause oxidative modification of proteins (Aksenov et al., 2001; Flora et al., 2003), as well as inflammation, gliosis, neuronal apoptosis and ventricular enlargement (Jones et al., 1998; Sabatier et al., 1991). Although Tat-induced apoptosis in the brain was confirmed in other studies (Gavriil et al., 2000; Zauli et al., 2000), the pathological relevance of these results may be called into question, considering the relatively high amounts inoculated (10 to $25 \mu \mathrm{g}$ ), that greatly exceed the concentrations of Tat ( 0.1 to $1 \mathrm{ng} / \mathrm{ml})$ found in the sera of HIV-1 infected patients (Westendorp et al., 1995). Evidence of apoptosis 
CC
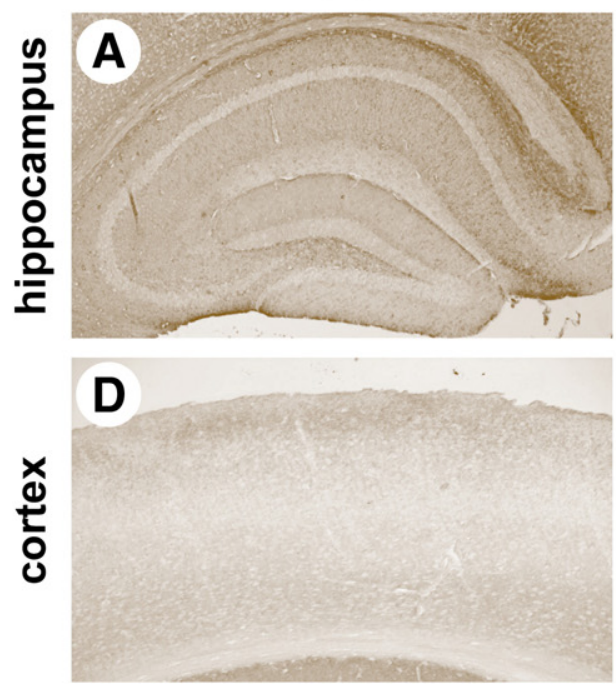

TT(L)
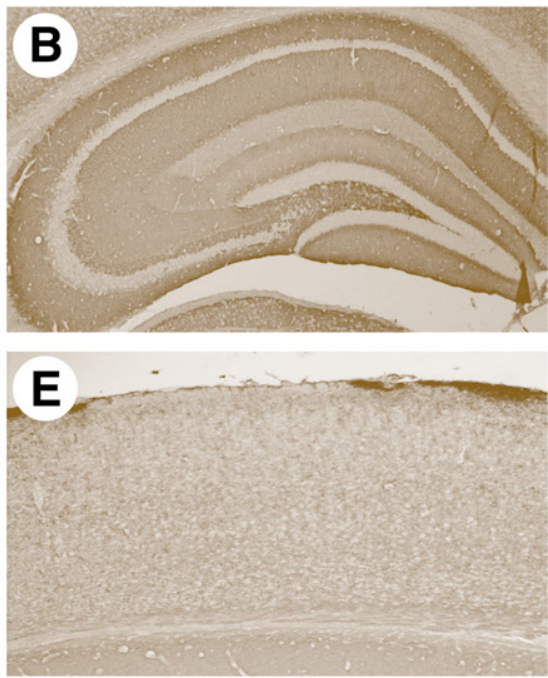

TT(H)
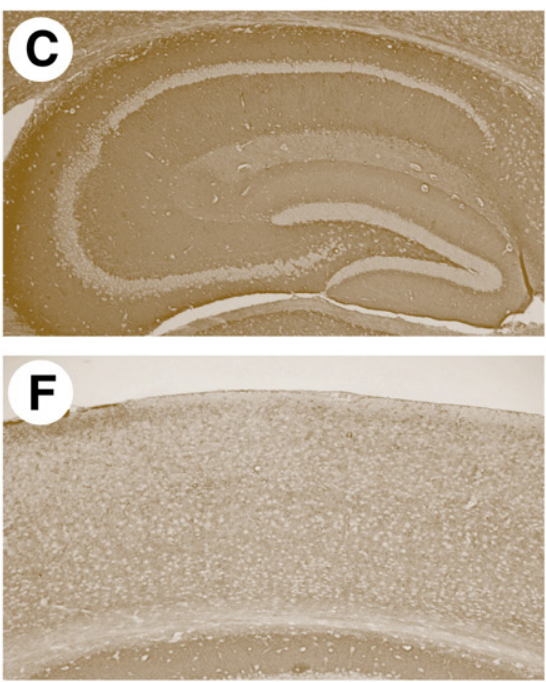

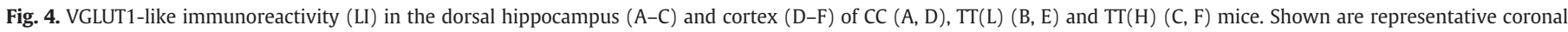

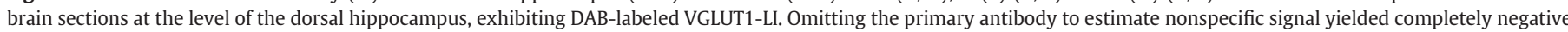
labeling (data not shown). Note a widespread increase in VGLUT1-LI in TT, and especially in TT(H), mice.

after inoculation in the striatum of the amounts of Tat (10 ng) that better approximate its levels in pathology has been more recently reported (Agrawal et al., 2007, 2012).

A second approach has been testing the effects of bath-applied Tat on neural cells. It has been found that Tat activates calcium release from $\mathrm{IP}_{3}$-sensitive intracellular stores (Haughey et al., 1999), and induces calcium influx in neural cells (Cheng et al., 1998) increasing cell death. Furthermore, Tat enhances glutamate-mediated excitotoxicity in neurons through the activation of NMDA receptors (Haughey et al., 2001; Li et al., 2008; Prendergast et al., 2002). Importantly, these latter effects were demonstrated at subtoxic concentrations, i.e. at concentrations close to those found clinically in serum. One intriguing implication of these observations is that, at clinically relevant concentrations, Tat per se may not produce neuronal damage, but increase the effects of neurotoxic agents that stimulate the release of glutamate, ultimately leading to the excessive activation of NMDA receptors.

Thus, these findings should be integrated with the analysis of possible effects at a presynaptic level. Again, initial studies have been conducted using acute, "pharmacological" administration, and proved that Tat can deeply influence central neurotransmission (Brailoiu et al., 2008; Eugenin et al., 2003; Feligioni et al., 2003; Ferris et al., 2009; Longordo et al., 2006; Musante et al., 2010; Zhu et al., 2009). These findings have been extended in the present study. We found that the effect of exogenous Tat is neurotransmitter- and area-specific. Tat did not affect the release of glutamate and GABA under basal condition, i.e. in the absence of depolarizing stimuli (Feligioni et al., 2003; Musante et al., 2010), but increased stimulus-evoked glutamate exocytosis in the hippocampus and cortex in TT mice, while GABA exocytosis was unchanged in the hippocampus and even decreased in the cortex.

As stated above for other kinds of studies, however, these findings are based on the acute administration of relatively high concentrations of Tat, and may not reflect the situation of chronic exposure to low concentrations as during HIV infection. In this sense, the TT model may be more predictive of the actual situation in human HAND patients. Consistent with the observation that acutely applied Tat does not affect the basal, unstimulated release of glutamate and GABA, its constitutive expression in TT mice also failed to affect the spontaneous release of both neurotransmitters. However, high $\mathrm{K}^{+}$-evoked glutamate overflow was significantly increased in the cortex and hippocampus of TT, as compared with control mice, while GABA overflow was reduced in the cortex and not altered in the hippocampus. These findings are perfectly coherent with those with acute Tat. Importantly, the intensity of all significant alterations in the release of glutamate and GABA correlated with tat gene expression levels and with the skin phenotype, suggesting that a direct relationship exists between the amount of Tat in the brain and functional alterations.
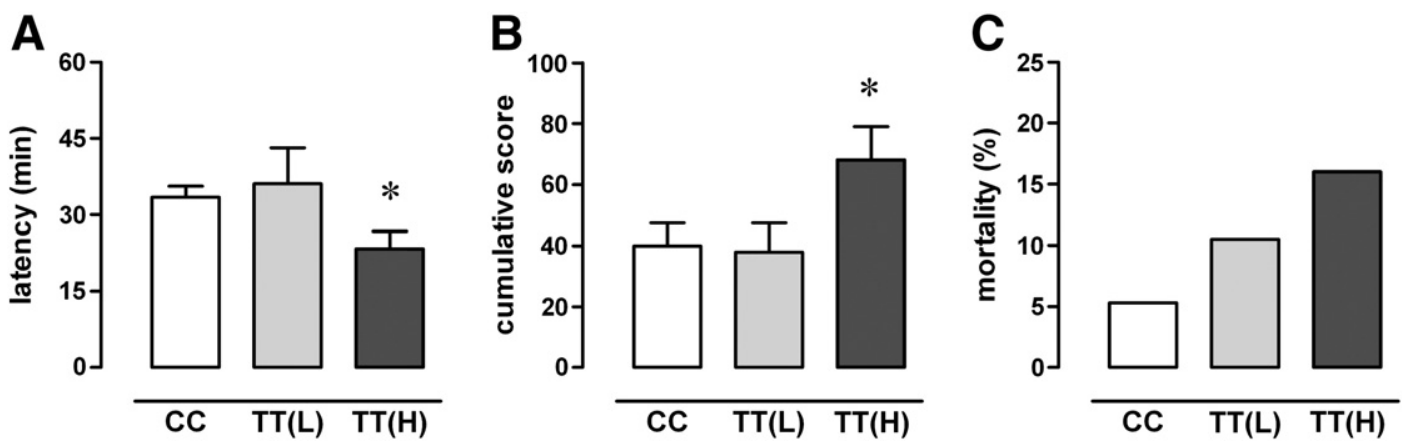

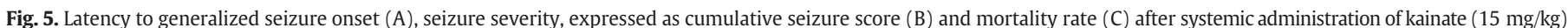

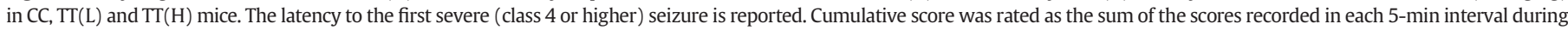

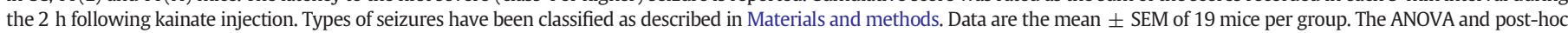
Newman-Keuls tests were used for the statistical analysis of latency and the Mann-Whitney $U$ test for the analysis of the cumulative score. ${ }^{*} \mathrm{P}<0.05$. 

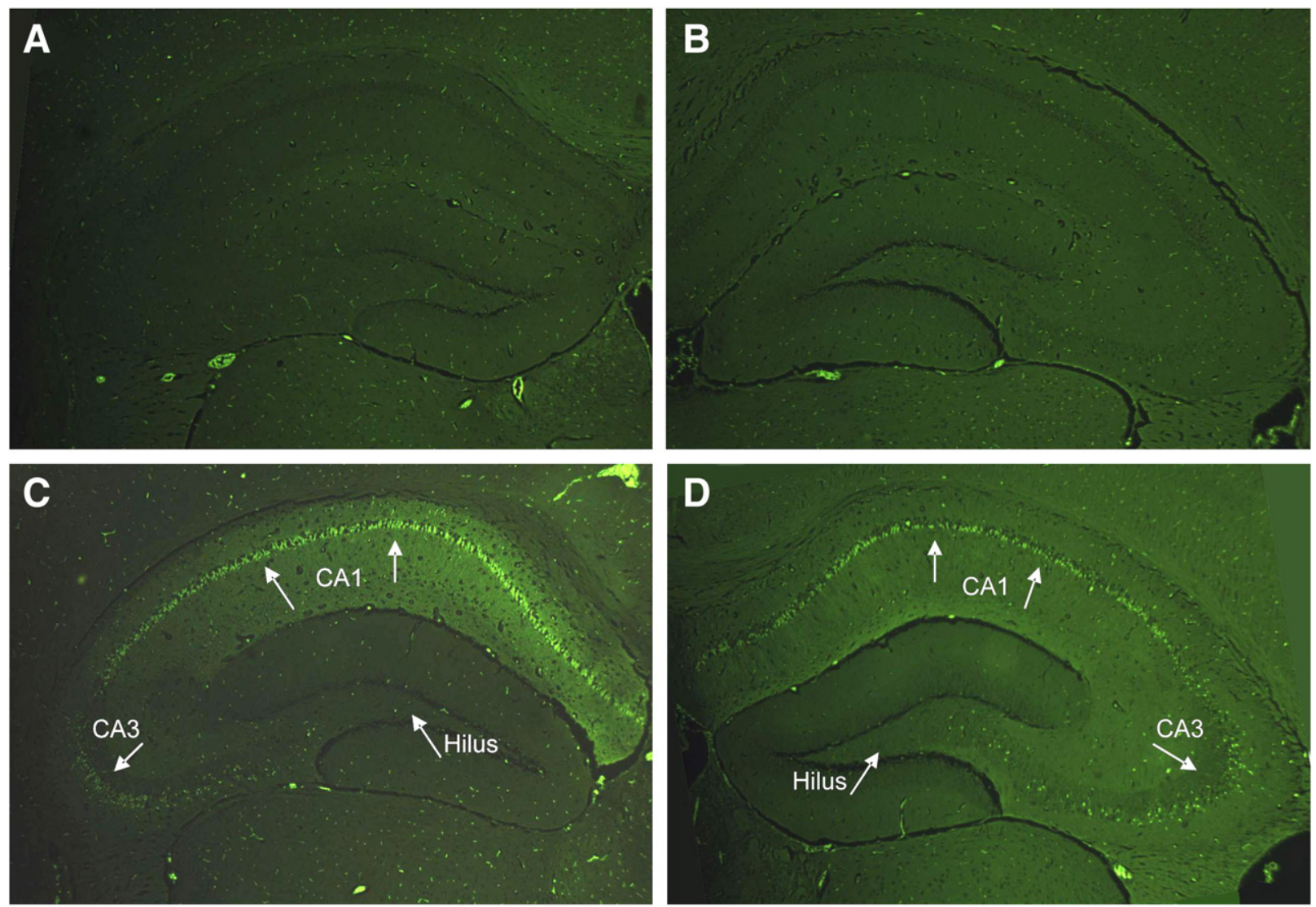

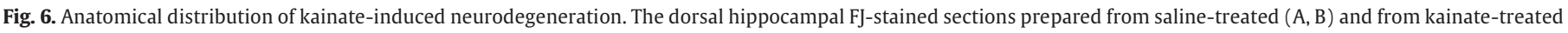

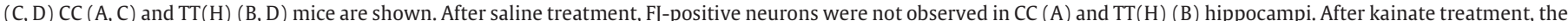

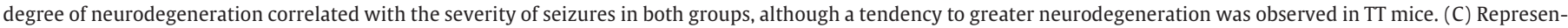

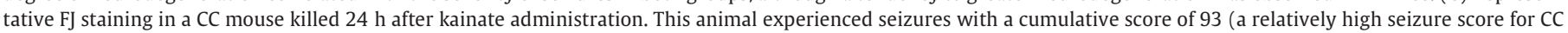

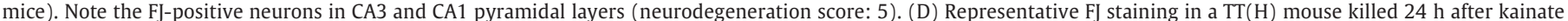

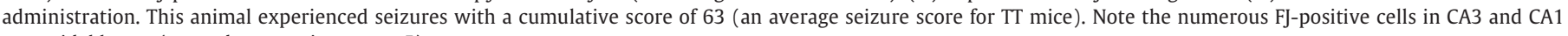
pyramidal layers (neurodegeneration score: 5 ).

It cannot be predicted if the Tat-induced changes in neurotransmitter exocytosis depend on the Tat interaction with cell membrane receptors or it implies its cellular translocation to the nucleus and modulation of gene expression. The first hypothesis is attractive because Tat is known to act as a promiscuous agonist at different receptors (mGluR1, NMDA, CCR2) most of which are differently located on glutamatergic and GABAergic nerve terminals (Brailoiu et al., 2008;

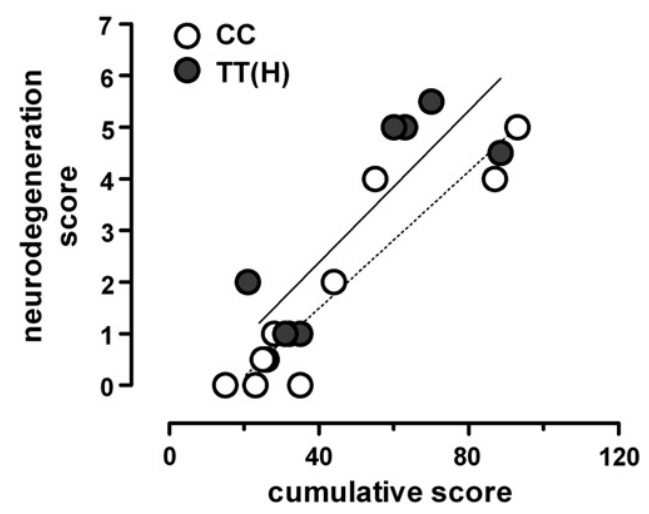

Fig. 7. Relationship between the severity of seizures (cumulative seizure score) and neurodegeneration (neurodegeneration score-similar results were obtained calculating the percentage of FJ-positive pixels). The linear regressions for control (CC, open circles, dashed line) and transgenic (TT(H), solid circles, solid line) mice are shown. Note that some TT(H) mice could not be included in the analysis because they died during the period of observation post-kainate injection.
Musante et al., 2010). In line with this hypothesis, chronic drug treatments influencing presynaptic receptor-mediated functions have been reported to cause neuronal adaptations that may be retained ex vivo, in isolated nerve terminals, where they emerge as changes in neurotransmitter exocytosis (Pittaluga et al., 2007). Changes in the exocytotic machinery in terms of the number of release vesicles or in terms of the efficiency of vesicular storage might account for these adaptive changes. This hypothesis is supported by our observation, consistent with the release data, that a marker of glutamate synaptic vesicles, GLUT1, is increased in the hippocampus and cortex of TT mice, in a Tat expression-dependent manner. This increased density of glutamate synaptic vesicles is likely to account for the observed increase in depolarization-evoked release.

Interestingly, the data obtained with low concentration Tat (including those reported here in TT mice) support the notion that its effects are stimulation-dependent: in the nervous tissue exposed to Tat, glutamate release is not altered under resting conditions whereas, when stimulation occurs, more glutamate than the normal is released (present data), allowing the activation of NMDA receptors that are phosphorylated (Haughey et al., 2001) and will elicit currents much greater than the normal, to a potentially dangerous level. Thus, the increased bioavailability of extracellular glutamate may represent a mechanism through which Tat exerts detrimental effects on neurons (Nath and Geiger, 1998). It should also be kept in mind that neurons do not represent the unique source of anomalous glutamate outflow, because Tat has been reported to increase glutamate spillover from astrocytes (Eugenin et al., 2003) and microglial cells (Gupta et al., 2010). Whether these events could be affected in TT mice remains to be established. 
The reduced stimulus-evoked GABA release at the cortical level also deserves some comments. It is well known that glutamate and GABA reciprocally modulate their release. In particular, GABA exerts a negative feedback on glutamate by activating presynaptic inhibitory $\mathrm{GABA}_{\mathrm{B}}$ heteroreceptors (Bonanno and Raiteri, 1993). The decreased stimulus-evoked GABA release in the TT cortex will attenuate this presynaptic mechanism of heteroregulation, further facilitating glutamate release and increasing the susceptibility to excitotoxicity. Based on our results, the cortex should be particularly exposed to neurotoxic events.

Taken together, these data strongly suggest that the balance between excitatory (glutamate) and inhibitory (GABA) neurotransmissions is highly unstable in the Tat-exposed brain, with a strong risk to lean pathologically towards hyper-excitation. This situation is expected to favor seizure susceptibility and seizure-related damage. In fact, seizures are often observed in HIV-1 infected patients (Dore et al., 1996) also in the absence of opportunistic infections (Bartolomei et al., 1999; Modi et al., 2002). Accordingly, Tat was reported to be epileptogenic when administered i.c.v. (Sabatier et al., 1991). Analysis of the susceptibility to kainate-induced seizures and neurodegeneration in the TT model seems particularly well suited to challenge this hypothesis, in that: 1) Tat concentration in the brain is very likely low and subtoxic, since we did not detect any overt neurological symptom or neuronal cell damage in TT mice under normal conditions, i.e. in the absence of excitatory stimuli; 2 ) the neurotoxic effect of kainate is largely dependent on the activation of NMDA receptors, being prevented by NMDA receptor antagonists (Virgili et al., 1992; Zucchini et al., 2002).

In line with expectation, we found that TT mice are highly susceptible to the effect of kainate and are predisposed to develop convulsive seizures leading to cell damage. The intensity of the seizures and of the neurodegeneration correlated with the levels of Tat in the brain and with the severity of the skin lesions, suggesting that both the brain syndrome and the skin phenotype are due to the expression of Tat in the different organs of TT mice. These observations are consistent with the concept that Tat facilitates excitotoxicity in vivo. Most likely, Tat alone cannot account for all aspects of HAND, but these results support its role as a key pathogenetic cofactor. As such, Tat may represent a molecular target for the prevention of HAND development in AIDS patients.

Supplementary data to this article can be found online at http:// dx.doi.org/10.1016/j.nbd.2013.02.004.

\section{Acknowledgments}

This work was supported by grants to AC from the National AIDS Project (Ministero della Sanità, Rome, Italy); grants to MS from the MIUR (Ministry for Instruction, University and Research) and from local funds of the University of Ferrara; and grants to AP from the MIUR (project no. 2009P7WHNR_003) and from local funds of the University of Genova (Progetto Ricerca Ateneo). PC work was supported by the RiMED Foundation.

We are grateful to A. Peverati, A. Bevilacqua, P. Zucchini, I. Pivanti and E. Magri for the excellent technical assistance and to A. Camerino for the animal care. We thank the FIT Biotech Oyj Plc, Tampere, Finland, the Centre for AIDS Reagents, the EU Programme EVA/MRC (contract QLKZ-CT-1999-00609), and the UK Medical Research Council for kindly providing us with the HIV-1 viral protein Tat and with a monoclonal Anti-Tat antibody.

\section{References}

Agrawal, L., et al., 2007. Preventing HIV-1 Tat-induced neuronal apoptosis using antioxidant enzymes: mechanistic and therapeutic implications. Virology 363, 462-472.

Agrawal, L., et al., 2012. HIV-1 Tat neurotoxicity: a model of acute and chronic exposure, and neuroprotection by gene delivery of antioxidant enzymes. Neurobiol. Dis. $45,657-670$.
Aksenov, M.Y., et al., 2001. Oxidative damage induced by the injection of HIV-1 Tat protein in the rat striatum. Neurosci. Lett. 305 (1), 5-8.

Albini, A., et al., 1998. HIV-1 Tat protein mimicry of chemokines. Proc. Natl. Acad. Sci. U. S. A. $95,13153-13158$.

Altavilla, G., et al., 1999. Morphological, histochemical, immunohistochemical, and ultrastructural characterization of tumors, dysplastic and non-neoplastic lesions arising in BK virus/tat transgenic mice. Am. J. Pathol. 154, 1231-1244.

Arya, S.K., et al., 1985. Trans-activator gene of human T-lymphotropic virus type III (HTLV-III). Science 229, 69-73.

Bartolomei, F., et al., 1999. Isolated, chronic, epilepsia partialis continua in an HIV-infected patient. Arch. Neurol. 56, 111-114.

Behnisch, T., et al., 2004. HIV secreted protein Tat prevents long-term potentiation in the hippocampal CA1 region. Brain Res. 1012, 187-189.

Bonanno, G., Raiteri, M., 1993. Functional evidence for multiple GABAB receptor subtypes in the rat cerebral cortex. J. Pharmacol. Exp. Ther. 262, 114-118.

Bradford, M.M., 1976. A rapid and sensitive method for the quantitation of microgram quantities of protein utilizing the principle of protein-dye binding. Anal. Biochem. $72,248-254$.

Brailoiu, G.C., et al., 2008. Excitatory effects of human immunodeficiency virus 1 Tat on cultured rat cerebral cortical neurons. Neuroscience 151, 701-710.

Bregola, G., et al., 2002. Involvement of the neuropeptide nociceptin/orphanin FQ in kainate seizures. J. Neurosci. 22, 10030-10038.

Bruce-Keller, A.J., et al., 2008. Morphine causes rapid increases in glial activation and neuronal injury in the striatum of inducible HIV-1 Tat transgenic mice. Glia 56, 1414-1427.

Chang, H.C., et al., 1997. HIV-1 Tat protein exits from cells via a leaderless secretory pathway and binds to extracellular matrix-associated heparan sulfate proteoglycans through its basic region. AIDS 12, 1421-1431.

Cheng, J., et al., 1998. Neuronal excitatory properties of human immunodeficiency virus type 1 Tat protein. Neuroscience 82, 97-106.

Corallini, A., et al., 1993. Systemic expression of HIV-1 tat gene in transgenic mice induces endothelial proliferation and tumors of different histotypes. Cancer Res. 53, 5569-5575

Dore, G.J., et al., 1996. Prospective analysis of seizure occurring in human immunodeficiency virus type-1 infection. J. NeuroAIDS 1, 59-69.

Dunkley, P.R., et al., 1986. A rapid method for isolation of synaptosomes on Percoll gradient. Brain Res. 372, 115-129.

Ensoli, B., et al., 1993. Release, uptake, and effects of extracellular human immunodeficiency virus type 1 Tat protein on cell growth and viral transactivation. J. Virol. 67, 277-287.

Eugenin, E.A., et al., 2003. MCP-1 (CCL2) protects human neurons and astrocytes from NMDA or HIV-tat-induced apoptosis. J. Neurochem. 85, 1299-1311.

Eugenin, E.A., et al., 2007. HIV-tat induces formation of an LRP-PSD-95-NMDAR-nNOS complex that promotes apoptosis in neurons and astrocytes. Proc. Natl. Acad. Sci. U. S. A. 104, 3434-3438.

Everall, I.P., et al., 1999. Cortical synaptic density is reduced in mild to moderate human immunodeficiency virus neurocognitive disorder. Brain Pathol. 9, 209-217.

Fadda, P., et al., 2007. Reduction of corticostriatal glutamatergic fibers in basic fibroblast growth factor deficient mice is associated with hyperactivity and enhanced dopaminergic transmission. Biol. Psychiatry 62, 235-242.

Feligioni, M., et al., 2003. The human immunodeficiency virus-1 protein Tat and its discrete fragments evoke selective release of acetylcholine from human and rat cerebrocortical terminals through species-specific mechanisms. J. Neurosci. 23, 6810-6818.

Ferrari, A., et al., 2003. Caveolae-mediated internalization of extracellular HIV-1 tat fusion proteins visualized in real time. Mol. Ther. 8, 284-294.

Ferris, M.J., et al., 2009. The human immunodeficiency virus-1-associated protein, Tat1-86, impairs dopamine transporters and interacts with cocaine to reduce nerve terminal function: a no-net-flux microdialysis study. Neuroscience 159, 1292-1299.

Flora, G., et al., 2003. Methamphetamine potentiates HIV-1 Tat protein-mediated activation of redox-sensitive pathways in discrete regions of the brain. Exp. Neurol. 179 (1), 60-70.

Frankel, A.D., Pabo, C.O., 1988. Cellular uptake of the Tat protein from human immunodeficiency virus. Cell 55, 1189-1193.

Gavriil, E.S., et al., 2000. Tat mediates apoptosis in vivo in the rat central nervous system. Biochem. Biophys. Res. Commun. 267 (1), 252-256.

Giulian, D., et al., 1990. Secretion of neurotoxins by mononuclear phagocytes infected with HIV-1. Science 250, 1593-1596.

Gupta, S., et al., 2010. HIV-Tat elicits microglial glutamate release: role of NAPDH oxidase and the cystine-glutamate antiporter. Neurosci. Lett. 485, 233-236.

Haughey, N.J., et al., 1999. Involvement of inositol 1,4,5-trisphosphate-regulated stores of intracellular calcium in calcium dysregulation and neuron cell death caused by HIV-1 protein Tat. J. Neurochem. 73, 1363-1374.

Haughey, N.J., et al., 2001. HIV-1 Tat through phosphorylation of NMDA receptors potentiates glutamate excitotoxicity. J. Neurochem. 78, 457-467.

Hudson, L., et al., 2000. Detection of human immunodeficiency virus regulatory protein Tat in CNS tissues. J. Neurovirol. 6, 145-155.

Janumpalli, S., et al., 1998. A point mutation (D79N) of the alpha2A adrenergic receptor abolishes the antiepileptogenic action of endogenous norepinephrine. J. Neurosci. 18, 2004-2008.

Jones, M., et al., 1998. Intraventricular injection of human immunodeficiency virus type 1 (HIV-1) tat protein causes inflammation, gliosis, apoptosis, and ventricular enlargement. J. Neuropathol. Exp. Neurol. 57 (6), 563-570.

Kaul, M., et al., 2005. HIV-1 infection and AIDS: consequences for the central nervous system. Cell Death Differ. 12, 878-892.

Kim, B.O., et al., 2003. Neuropathologies in transgenic mice expressing human immunodeficiency virus type 1 Tat protein under the regulation of the astrocyte-specific glial fibrillary acidic protein promoter and doxycycline. Am. J. Pathol. 162, 1693-1707.

King, J.E., et al., 2006. HIV Tat and neurotoxicity. Microbes Infect. 8, 1347-1357.

Li, W., et al., 2008. NMDA receptor activation by HIV-Tat protein is clade dependent. J. Neurosci. 28, 12190-12198. 
Lindl, K.A., et al., 2010. HIV-1 associated neurocognitive disorder: pathogenesis and therapeutic opportunities. J. Neuroimmune Pharmacol. 5, 294-309.

Longordo, F., et al., 2006. The human immunodeficiency virus-1 protein Tat upregulates NMDA receptor function by acting at mGluR1 receptors coexisting on human and rat brain noradrenergic neurons. J. Pharmacol. Exp. Ther. 317, 1097-1105.

Luccini, E., et al., 2007. N-methyl-D-aspartate autoreceptors respond to low and high agonist concentrations by facilitating, respectively, exocytosis and carriermediated release of glutamate in rat hippocampus. J. Neurosci. Res. 85, 3657-3665.

Masliah, E., et al., 1992. Spectrum of human immunodeficiency virus-associated neocortical damage. Ann. Neurol. 32, 321-329.

Mengozzi, M., et al., 1999. Human immunodeficiency virus replication induces monocyte chemotactic protein-1 in human macrophages and U937 promonocytic cells. Blood 93, 1851-1857.

Minghetti, L., et al., 2004. Multiple actions of the human immunodeficiency virus type1 Tat protein on microglial cell functions. Neurochem. Res. 29, 965-978.

Modi, G., et al., 2002. New onset seizures in HIV-infected patients without intracranial mass lesions or meningitis-a clinical, radiological and SPECT scan study. J. Neurol. Sci. 202, 29-34.

Musante, V., et al., 2010. The HIV-1 viral protein Tat increases glutamate and decreases GABA exocytosis from human and mouse neocortical nerve endings. Cereb. Cortex 20, 1974-1984.

Musante, V., et al., 2011. Presynaptic glycine GlyT1 transporter-NMDA receptor interaction: relevance to NMDA autoreceptor activation in the presence of $\mathrm{Mg}^{2+}$ ions. J. Neurochem. 117, 516-527.

Muzzolini, A., et al., 1997. Characterization of glutamate and [3H]D-aspartate outflow from various in vitro preparations of the rat hippocampus. Neurochem. Int. 31, 113-124.

Nath, A., Geiger, J.D., 1998. Neurobiological aspects of HIV infections: neurotoxic mechanisms. Prog. Neurobiol. 54, 19-33.

Navia, B.A., Jordan, B.D., Price, R.W., 1986. The AIDS dementia complex: I. Clinical features. Ann. Neurol. 19, 517-524.

Paradiso, B., et al., 2009. Localized delivery of fibroblast growth factor-2 and brainderived neurotrophic factor reduces spontaneous seizures in an epilepsy model. Proc. Natl. Acad. Sci. U. S. A. 106, 7191-7196.

Paxinos, G., Franklin, K.B.J., 2001. The Mouse Brain in Stereotaxic Coordinates, Second edition. Academic Press, New York.

Peng, J., et al., 2010. The HIV-1 transgenic rat as a model for HIV-1 infected individuals on HAART. J. Neuroimmunol. 218 (1-2), 94-101.
Pittaluga, A., et al., 2007. Antidepressant treatments and function of glutamate ionotropic receptors mediating amine release in hippocampus. Neuropharmacology 53, 27-36.

Prendergast, M.A., et al., 2002. Neurotoxic effects of the human immunodeficiency virus type-1 transcription factor Tat require function of a polyamine sensitive-site on the N-methyl-D-aspartate receptor. Brain Res. 954, 300-307.

Raiteri, L., Raiteri, M., 2000. Synaptosomes still viable after 25 years of superfusion. Neurochem. Res. 25, 1265-1274.

Sabatier, J.M., et al., 1991. Evidence for neurotoxic activity of tat from human immunodeficiency virus type 1. J. Virol. 65, 961-967.

Schmued, L.C., Hopkins, K.J., 2000. Fluoro-Jade B: a high affinity fluorescent marker for the localization of neuronal degeneration. Brain Res. 874, 123-130.

Schwarze, S.R., et al., 1999. In vivo protein transduction: delivery of a biologically active protein into the mouse. Science 285 (5433), 1569-1572.

Selnes, O.A., 2005. Memory loss in persons with HIV/AIDS: assessment and strategies for coping. AIDS Read. 15, 289-292.

Singer, E.J., et al., 2010. Neurological presentation of AIDS. Neurol. Clin. 28, 253-275.

Tattevin, P., et al., 2006. Confusion, memory disorders, and ophthalmoparesis in a patient with AIDS. Lancet 367, 368.

Virgili, M., et al., 1992. Protection from kainic acid neuropathological syndrome by NMDA receptor antagonists: effect of MK-801 and CGP 39551 on neurotransmitter and glial markers. Neuropharmacology 5, 469-474.

Wessenligh, S.L., 1993. Intracerebral cytokine messenger RNA expression in acquired immunodeficiency syndrome dementia. Ann. Neurol. 33, 576-582.

Westendorp, M.O., et al., 1995. Sensitization of T cells to CD95-mediated apoptosis by HIV-1 Tat and gp120. Nature 375, 497-500.

Zauli, G., et al., 2000. HIV-1 Tat-mediated inhibition of the tyrosine hydroxylase gene expression in dopaminergic neuronal cells. J. Biol. Chem. 275 (6), 4159-4165.

Zhu, J., et al., 2009. HIV-1 Tat protein-induced rapid and reversible decrease in [3H] dopamine uptake: dissociation of $[3 \mathrm{H}]$ dopamine uptake and $[3 \mathrm{H}] 2$ betacarbomethoxy-3-beta-(4-fluorophenyl)tropane (WIN 35,428) binding in rat striatal synaptosomes. J. Pharmacol. Exp. Ther. 329, 1071-1083.

Zucchini, S., et al., 2002. Neuroprotective activity of CHF3381, a putative N-methyl-Daspartate receptor antagonist. NeuroReport 13, 2071-2074.

Zucchini, S., et al., 2008. FGF-2 overexpression increases excitability and seizure susceptibility but decreases seizure-induced cell loss. J. Neurosci. 49, 13112-13124. 